\title{
Research and Analysis On the Electromagnetic Interference Characteristic of SVG Power Module
}

\author{
Chengchang Liu1, Ye Lu2, Xin Yu1, Xiaolin Deng1, Jun Zhang1, \\ Guangming Yu3 \\ 1State Grid Liaoning Electric Power Supply Co., Ltd. Dandong Power \\ Supply Branch, Dandong, Liaoning 118000, China \\ 2Periodical Office of China Rural Finance, Beijing 100080, China \\ 3Rongxin Power Electronic Co., Ltd., Anshan, Liaoning 114051, China
}

\begin{abstract}
SVG is the third generation static var compensator that performs reactive power regulation by sending out capacitive or inductive current. Since numerous high power electronic components (GTO, IGBT) and PWM technology are used, the intensity and type of electromagnetic interference generated by frequent $\mathrm{ON} / \mathrm{OFF}$ in a short time are far more than traditional var compensators such as capacitor bank, which threatens the safe operation of SVG body and other electrical equipments nearby. As a core component of SVG, power unit is also the most important electromagnetic interference source in SVG. This document analyzes and studies the generating mechanism of electromagnetic interference by power unit and the features of electromagnetic interference, and provides reference for further improving electromagnetic compatibility of SVG.
\end{abstract}

Keywords: SVG, IGBT, differential mode interference, common mode interference

\section{Introduction}

The SVG in power system is generally installed in a substation where there are many primary or secondary equipments, so electromagnetic interference problem must be considered in product design. SVG electromagnetic interference is divided into two categories: generated by power switching components in the device (GTO, IGBT) during work and generated by electromagnetic equipments (connecting reactor) in the device during work. Since connecting reactors are not main components of SVG, the electromagnetic interference caused by power switching components in SVG is mainly discussed in this paper. Division as per frequency is shown in Table 1.

Table 1 Classification of Main Electromagnetic Interference in SVG

\begin{tabular}{|l|l|l|}
\hline Frequency & Interference type & $\begin{array}{l}\text { Interference propagation } \\
\text { mode }\end{array}$ \\
\hline
\end{tabular}




\begin{tabular}{|l|l|l|}
\hline 1 to $4 \mathrm{MHz}$ & Common mode & Conduction \\
\hline 5 to $8 \mathrm{MHz}$ & Common mode & Conduction \\
\hline $\begin{array}{l}10 \text { to } \\
20 \mathrm{MHz}\end{array}$ & Common mode & Conduction \\
\hline $\begin{array}{l}30 \text { to } \\
40 \mathrm{MHz}\end{array}$ & Differential mode & Radiation \\
\hline
\end{tabular}

It may be seen from Table 1 that, common mode interference and differential mode interference coexist in SVG. Wherein interference below $30 \mathrm{MHz}$ may be propagandized to each component in SVG via conductor, and direct radiation propagation is possible for the interference above $30 \mathrm{MHz}$. The damages to SVG caused by these electromagnetic interferences include the following:

1. Interference to sampling system. SVG controls power unit to send out capacitive or inductive current to regulate reactive power by acquiring current, voltage signals in real time. The Hall element for acquiring SVG output current signal is installed in power unit accessories in the power room, therefore, the interference signal may influence SVG control accuracy directly, even lead to equipment trip, especially in case of closed loop control of SVG.

2. Interference to control system. SVG control board system contains a large number of high speed chips, commonly including DSP, FPGA chip etc. While peak interference signal may cause shutdown, reset of the chips via switch power supply, or cause program "fleet" via clock signal.

3 . Interference to protection system. Some protective contactors and circuit breakers are installed in SVG. Interference signal might cause "malfunction" or "failure to operate" of these components, lead to equipment trip or damage.

4. Interference to communication system. SVG generally adopts industrial PC to realize the communication with upper level system, interference signal may lead to abnormal work, and even damage of industrial PC via power supply or communication cable.

It is noteworthy that, electromagnetic interference sometimes might also lead to erroneous trigger of IGBT, damage driver board card of IGBT module. After summarizing the damages to SVG caused by electromagnetic interference, generating mechanism of electromagnetic interference in SVG is analyzed below. Generating Mechanism of Electromagnetic Interference by Power Module The largest interference source in SVG is IGBT and freewheeling diode in power unit, rather than switch power supply or connecting reactor. This is because operating frequency of IGBT in SVG is up to Hz, voltage on both terminals is very high (V), current is also heavy (A), di/dt, du/roughtly change rate of the components is far more than other electronic components. Table 2 shows statistics of the change rate of current, voltage at each stage during ON/OFF of certain type of IGBT.

Table 2 Change Rate of Current, Voltage During ON/OFF of IGBT

\begin{tabular}{|l|l|l|}
\hline Stage & $\begin{array}{l}\text { Voltage change rate }(\mathrm{dv} / \mathrm{dt}) \\
(\mathrm{V} / \mu \mathrm{s})\end{array}$ & $\begin{array}{c}\text { current change rate }(\mathrm{di} / \mathrm{dt}) \\
(\mathrm{A} / \mu \mathrm{s})\end{array}$ \\
\hline$\tau_{1}$ & -41.5 & 41.7 \\
\hline
\end{tabular}




\begin{tabular}{|l|l|l|}
\hline$\tau_{2}$ & -523 & -5.7 \\
\hline$\tau_{3}$ & -87.5 & 0 \\
\hline$\tau_{4}$ & 55.2 & 0 \\
\hline$\tau_{5}$ & 1012 & -10.2 \\
\hline$\tau_{6}$ & 1012 & -37.5 \\
\hline$\tau_{7}$ & -405 & 0 \\
\hline
\end{tabular}

Note: ${ }^{\tau_{1}}$ to $\tau_{7}$ refer to the stages of IGBT from ON to OFF.

It may be seen that $\mathrm{dv} / \mathrm{dt}$ is up to $1012 \mathrm{~V} / \mu \mathrm{s}$, $\mathrm{di} / \mathrm{dt}$ is up to $41.7 \mathrm{~A} / \mu \mathrm{s}$. Take an example of $10 \mathrm{kV} \pm 5 \mathrm{M} \mathrm{SVG}$, totally 144 pieces of IGBT are installed, very large sudden change energy might be generated during equipment operation (hundreds of nanoseconds).

Just as all electric power electronic modules, parasitic inductance, parasitic capacitance exist in SVG power module, see Table 3. When interference source acts on the LC loop formed by these parasitic capacitances and parasitic inductances, it is converted to electromagnetic interference, generates common mode noise and differential mode noise.

It should be specifically pointed out that, since IGBT module generates a large quantity of heat during work, so it is installed on the radiator via heat conducting base plate (insulated), at the same time, radiator needs to be grounded, this is also a reason that generates noise.

Table 3 Parasitic Inductance and Capacitance Values of the Components in the Power Module

\begin{tabular}{|l|l|l|}
\hline Components & $\begin{array}{l}\text { Parasitic } \\
\text { inductance } \\
\text { value }\end{array}$ & $\begin{array}{l}\text { Parasitic } \\
\text { capacitance value }\end{array}$ \\
\hline IGBT & 20 to 40nh & $100-200 \mathrm{pf}$ \\
\hline $\begin{array}{l}\text { Between P and N } \\
\text { poles (IGBT) }\end{array}$ & 20 to 40nh & \\
\hline $\begin{array}{l}\text { Absorption } \\
\text { capacitor }\end{array}$ & & $600-1000 \mathrm{pf}$ \\
\hline Insulated base plate & & \\
\hline
\end{tabular}

Electromagnetic interference features of the power module

Fig. 1 shows the analysis of common mode interference of SVG power module. It may be seen that, conducted noise amplitude of the entire power module decreases progressively in the range of $0.15 \mathrm{MHz}-2 \mathrm{MHz}$ and the range of $3 \mathrm{MHz}-30 \mathrm{MHz}$, while amplitude fluctuation exists in the range of $2 \mathrm{MHz}-3 \mathrm{MHz}$. This is because electromagnetic noise in this frequency range mainly depends on ON/OFF characteristic of IGBT(GTO) in the power unit. For example, in IGBT ON/OFF process, voltage rise and fall time is about 50-100ns, the frequency of corresponding electromagnetic noise is $2-3 \mathrm{MHz}$. 


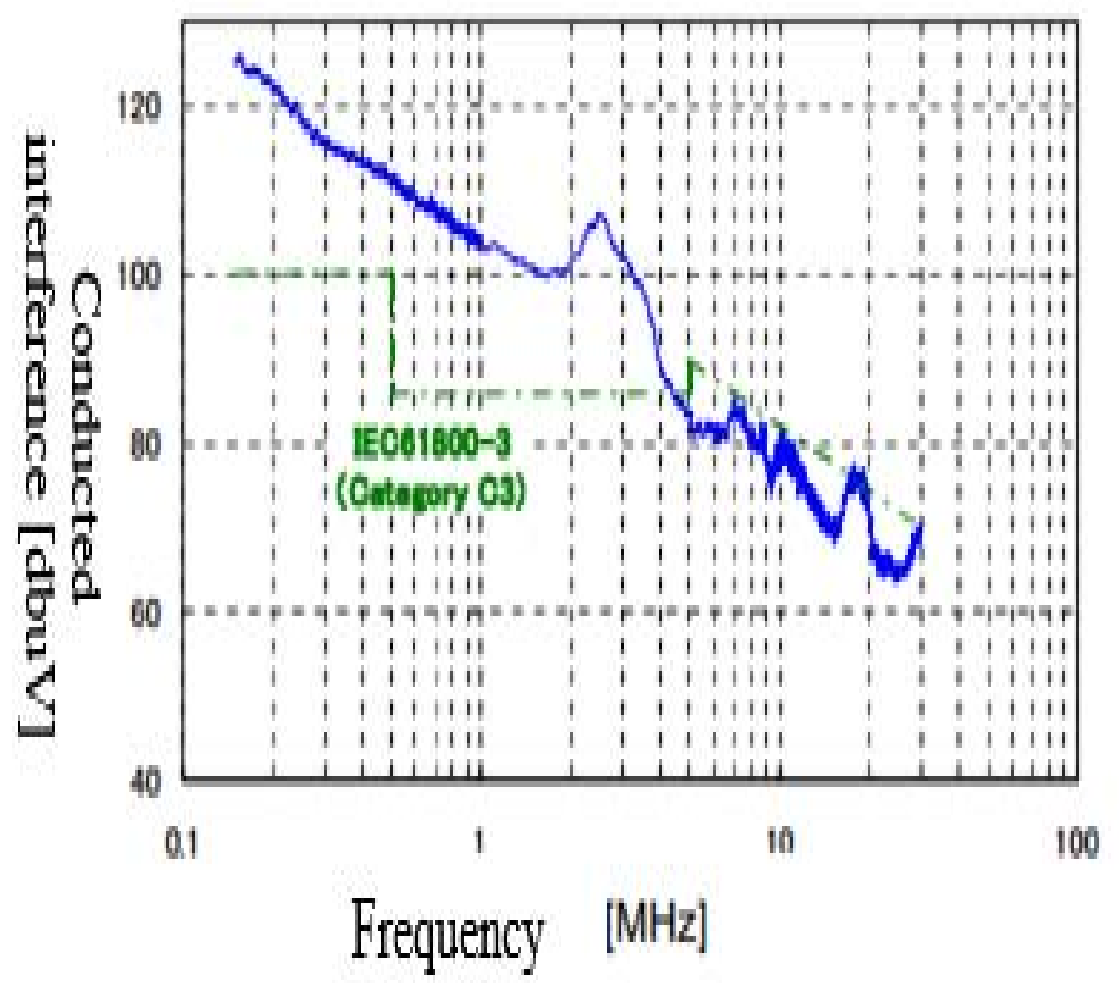

Fig. 1 Conducted Noise Frequency Spectrum of the Power Module 


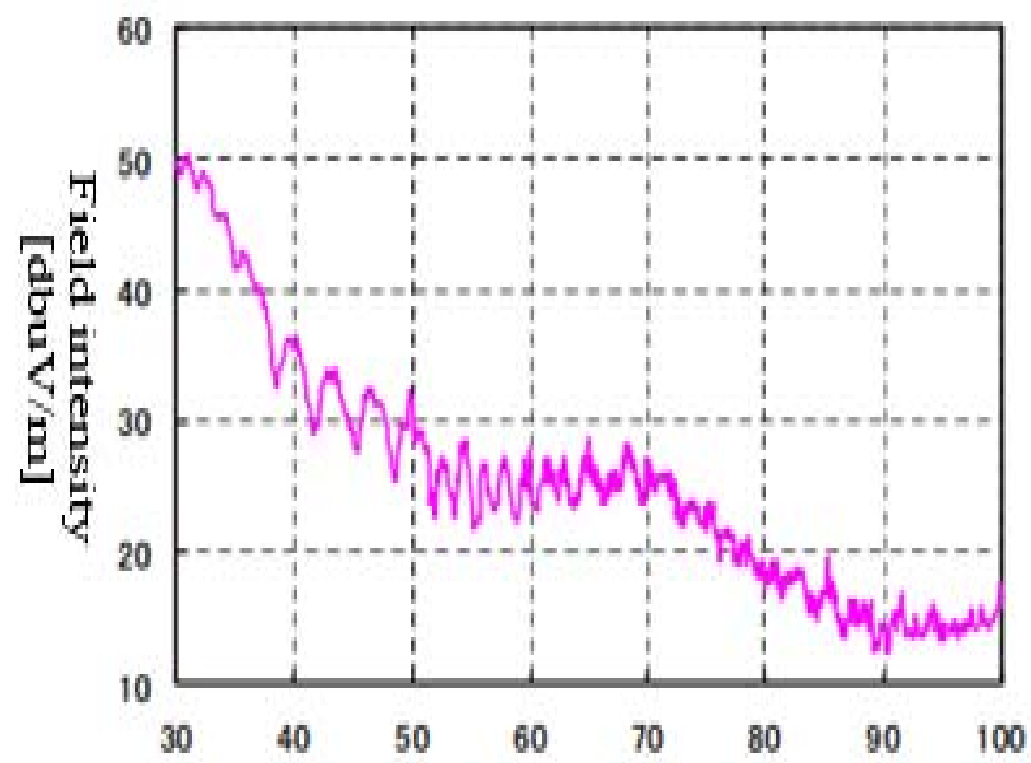

Fig. 2 Radiated Noise Frequency Spectrum of the Power Module

It may be seen from the analysis of differential mode interference of SVG power module in Fig. 2 that, radiated noise frequency domain of power module is very wide, from $30 \mathrm{MHz}$ to $100 \mathrm{MHz}$, but basically decreases progressively.

\section{Conclusion}

The power unit in SVG may generate large common mode electromagnetic interference and differential mode electromagnetic interference, amplitude of common mode electromagnetic interference is related to voltage on both terminals and through current of the power unit, frequency range is related to ON/OFF characteristic of IGBT components; frequency domain of differential mode electromagnetic interference is very wide, it attenuates gradually with the increase of frequency.

\section{References}

[1] Luo Chenglian "Principle and Realization of Static Reactive Synchronous Compensator (STATCOM)" [M]. Beijing: China Electric Power Press, 2005;

[2] Jackbson B,Karlsson P,Asplund G, et al. VSC-HVDC transmission with cascaded two-level converters[J].proc.Cigre,2010:B4-110. 
[3] Grbovic P J. An IGBT gate drive for feed-forward control of turn-on losses and reverse recovery current[J]. Power Electronics, IEEE Transactions on, 2008,23(2):643-652

[4] Khanna VK. Insulated Gate Bipolar Transistor IGBT Theory and Design[M].John Wiley\&Sons,2004

[5] Yang Yihan. Fundamental of Electrical Power System [M]. Beijing: China Water \& Power Press, 1986. 